\title{
Overcoming Inaction through Collective Institutional Entrepreneurship: Insights from Regime Theory
}

\author{
February 9, 2007 \\ Frank Wijen \\ Department of Strategic Management and Business Environment \\ RSM Erasmus University \\ Burg. Oudlaan 50 \\ 3062 PA Rotterdam, The Netherlands \\ E-mail: fwijen@rsm.nl \\ Phone: 0031- 10- 4081985 \\ Fax: 0031- 10- 4089013 \\ Shahzad Ansari \\ Department of Strategic Management and Business Environment \\ RSM Erasmus University \\ Burg. Oudlaan 50 \\ 3062 PA Rotterdam, The Netherlands \\ E-mail: sansari@rsm.nl \\ Phone: 0031- 10- 4081996 \\ Fax: 0031- 10- 4089013
}

\section{Accepted for publication in Organization Studies (2007/7)}

\section{Acknowledgements}

We gratefully acknowledge the constructive comments of OS guest editor Steve Maguire, two anonymous OS reviewers, Bas Koene, David Levy, Kamal Munir, David Reiner, Arjen Slangen, Charlotte Streck, and Paul Vlaar on earlier versions, as well as the contribution of Kees Zoeteman to the data collection. 


\begin{abstract}
Studies on institutional change generally pertain to the agency-structure paradox or the ability of institutional entrepreneurs to spearhead change despite constraints. In many complex fields, however, change also needs cooperation from numerous dispersed actors. This presents the additional paradox of ensuring that these actors engage in collective action when individual interests favor lack of cooperation. We draw on complementary insights from institutional and regime theories to identify drivers of collective institutional entrepreneurship and develop an analytical framework. This is applied to the field of global climate policy to illustrate how collective inaction was overcome to realize a global regulatory institution, the Kyoto Protocol.
\end{abstract}

Key words: collective institutional entrepreneurship, institutional theory, regime theory, collective action, public policy, climate change, global regulatory institution, Kyoto Protocol 
To account for institutional change, most studies focus on institutional entrepreneurship (e.g., DiMaggio 1988), where purposeful actors leverage their social and political skills and spearhead change (Fligstein 1997; Garud et al. 2002). With only a few 'key' entrepreneurs, agency or purposeful action is relatively concentrated with a high degree of coordination between the actors (Dorado 2005). However, many institutional changes are complex social processes involving highly diverse interests and perspectives. This type of institutional change, initiated through 'convening' (Dorado 2005), requires collective action - joint activities by a wide group of actors on the basis of mutual interests (Emery and Trist 1965; Marwell and Oliver 1993) - and is beyond the capacity of individual actors or even a few key entrepreneurs. Institutional change in such domains requires 'collective institutional entrepreneurship’ (Möllering 2007), a term that we define as the process of overcoming collective inaction and achieving sustained collaboration among numerous dispersed actors to create new institutions or transform existing ones.

Collective institutional entrepreneurship involves ‘collaborative leadership’ (Chrislip and Larson 1994), a form of leadership enacted not just by guiding actors but also through other media such as structures and processes embedded within a collaboration (Huxham and Vangen 2000). It also requires ‘institutional work’ or “practices that go well beyond those of institutional entrepreneurs” (Lawrence and Suddaby 2006: 215) which include the purposive actions of multiple individuals and organizations, entrepreneurial as well as supportive, aimed at creating, maintaining, and disrupting institutions. Since collective interests do not always produce collective action (Heckathorn 1996), it becomes necessary, however, to not only bring collective resources to bear on the problem (Westley and Vredenburg 1997) but also to provide motivations to individual participants whose interests may lie in not cooperating. In other words, these situations present a collective action dilemma (Oliver 1993). Since most research endeavors have focused on either institutional change with concentrated agency or on 
dispersed agency without the need to coordinate, institutional entrepreneurship that depends on collaboration among numerous dispersed agents is a gap that needs scholarly attention (Dorado 2005).

Change in collective action domains constitutes a double paradox. Apart from having to reconcile the agency-structure paradox or the ability of actors to spearhead change despite constraints (Seo and Creed 2002), actors need to resolve a collective action problem in which individual interests may work against cooperation and promote collective inaction. Different causes underlie collective inaction. First, individuals may want to free-ride on the contributions of others (Olson 1965). Second, a start-up problem may occur where action gets held up because all actors are waiting for others to take the lead (Marwell and Oliver 1993). Third, there may be actor apathy, where actors abstain from engaging in collective action because they feel their contribution to the problem is insignificant (Fireman and Gamson 1979). All these factors make non-participation and inaction rather than cooperation the likely outcome (Heckathorn 1996).

Since explaining cooperation in collective action domains has not been the main focus of research in institutional theory, we draw on insights from regime theory (Hasenclever et al. 1997; Keohane 1984), which provides complementary insights into explaining collective institutional entrepreneurship. Regime theory focuses on how actors, generally at the state level, overcome the collective action problem and realize collaboration in areas serving their common interests despite the absence of a supranational authority. The use of regime theory resonates with the growing recognition of the contributions of many different literatures to the ‘cross-pollination’ of institutional theory (Lounsbury and Ventresca 2002), particularly from structuration (Barley and Tolbert 1997), social movements (Rao et al. 2000), the resourcebased view (Oliver 1997), transaction cost economics (Roberts and Greenwood 1997), and technological innovation (Van de Ven and Garud 1993). Using the strengths in one theory to 
address the weaknesses in another can provide a more nuanced and multi-faceted perspective in understanding collective institutional entrepreneurship.

We combined insights from institutional and regime theories to develop a theoretical framework and applied it to climate change, one of the most salient global problems of our times. Initiating and promoting new public policy at the global level in an area characterized by conflicting interests was a classic collective-action challenge that in 2005 led to the entryinto-force of a formal 'global regulatory institution' (Maguire and Hardy 2006), the Kyoto Protocol. We analyzed how and why most nation states have increasingly cooperated in the field of global climate policy despite widely divergent interests and viewpoints. Our main contribution is to provide and apply a multi-faceted analytical framework to explain the creation of new institutions in a complex and controversial context.

The paper is structured as follows. We first present the challenge of institutional entrepreneurship and change requiring collective action. We then draw on institutional and regime theories to set up a framework of the drivers of such change. Next, we apply the framework to the institutional field of global climate policy. We conclude with implications for theory and practice.

\section{THEORETICAL FRAMEWORK}

In situations where groups of stakeholders are concerned about a common issue or problem such as environmental degradation, the only route to achieving change is by developing collaborative solutions (Gray 1989; Hardy and Phillips 1998; Trist 1983) and a ‘collective logic of action’ (Lincoln et al. 1996). Despite the 'real-world' importance of such complex domains, institutional scholars have paid little attention to collective institutional entrepreneurship, notwithstanding a few exceptions (e.g., Phillips et al. 2000). Indeed, most 
studies tend to focus on the agency-structure paradox and the role of individual actors or a few key entrepreneurs, rather than on the challenges posed by the collective action paradox.

\section{Institutional Entrepreneurship and Change}

Institutional theory continues to provide useful insights into explaining not only the homogeneity and persistence of institutions but also their change and transformation (Dacin et al. 2002). Institutions are products of purposive human action (Jepperson 1991), consisting of “cultural-cognitive, normative and regulative elements” (Scott 2001: 48) that provide stability and meaning to social life. While institutions can be both formal and informal (North 1990) and may exist at the micro, field, or societal levels (Lawrence and Suddaby 2006), our focus is on formal global regulatory institutions (Maguire and Hardy 2006). In explaining institutional change, the role of exogenous events or 'jolts', such as economic shocks, in precipitating nonisomorphic change is widely acknowledged (e.g., Hoffman 1999). However, increasing attention is being paid to 'endogenously' driven institutional change, where purposeful actors overcome the agency-structure paradox (e.g., Greenwood and Suddaby 2006).

Scholars have explained institutional change by drawing on insights from three main ‘schools’ within institutional theory. Hirsch and Lounsbury (1997) have called for integrating insights from the 'old institutionalism', with its focus on issues of agency, vested interests, power, and informal structures (Selznick 1949), with those from 'new institutionalism', stressing structural constraints, embeddedness, and isomorphism (DiMaggio and Powell 1991). The third school, institutional economics, emphasizes human agency in devising institutions "that structure political, economic and social interaction" (North 1990: 97). In theorizing about agency, most scholars invoke the role of institutional entrepreneurs (Aldrich

and Fiol 1994; Garud et al. 2002; Greenwood and Suddaby 2006; Maguire et al. 2004). Institutional entrepreneurs exercise social and political skills (Fligstein 1997; Garud et al. 
2002) to motivate others by providing them with common meaning and identities and manipulate existing institutions by co-opting important constituencies (Beckert 1999) in a process that has been described as 'leveraging' (Dorado 2005).

Many sector-spanning institutional fields are, however, too complex for these key entrepreneurs to spearhead change unilaterally (Huxham and Vangen 2000; Trist 1983) and need 'institutional work' from a broad spectrum of actors (Lawrence and Suddaby 2006) who need to act in unison and share responsibilities (Greenwood and Suddaby 2006). While cooperation among disparate groups which leads to change in such cross-organizational fields has not received much attention in institutional theory (Dorado 2005), a substantial body of 'non-institutional' organizational literature has addressed how interorganizational collaboration between interdependent actors can induce change in such problem domains (Gray 1989; Ring and Van de Ven 1994).

The primary focus of the literature on collaboration has been on "collaborative advantage, in which something is achieved that could not have been achieved without collaboration", rather than on the dilemmas inherent in collaboration (Huxham and Vangen 2000: 1160). While research in interorganizational collaboration highlights the characteristics of key actors in achieving successful collaboration, less attention is paid to the strategies they use to overcome collective inaction (Oliver 1993) and induce cooperation among unaware, unsure, or skeptical actors in the absence of hierarchy. In short, we know more about the types of actors that facilitate collaboration than about their actual activities.

A particularly significant arena for studying such cooperation is that of international relations, where regime theory scholars have grappled with the question of how global cooperation can occur in a world system comprised of sovereign nation states without a global government to make and enforce rules (Rittberger 1995; Young 1989). While scholars have used organizational theory to make valuable cross-cutting forays into international relations in 
issues such as the escalation of conflicts (Kahn and Zald 1990), the reciprocal insights have been far less compelling (Louis and Gray 1992). We argue that regime-theoretic insights have significant potential to inform organizational theory, in particular the notion of collective institutional change.

\section{Regime Theory and Collective Action}

Since we are drawing on a stream from international relations which is not commonly used in organizational theory, we first provide a brief overview of regime theory, its various schools of thought, and the parallels it has with institutional theory.

\section{A Synopsis of Regime Theory}

Regime theory explains collective decision making and implementation aiming at the management and resolution of international conflicts through the development of regimes (Hasenclever et al. 1997; Keohane 1984). Regimes are defined as social institutions consisting of agreed on principles, norms, rules, decision-making procedures, and programs around which actors' expectations converge in specific issue areas within the world system (Young 1989).

The core constructs used in regime analysis are compatible with an institutional approach (Scott 2001; Volger 2003). In many ways, regime theory is thus a theory of international institutions that have typically been formalized into explicit laws (Volger 2003), similar to what Maguire and Hardy (2006) describe as global regulatory institutions. The arena of regimes generally involves multi-level governance and is formed around a common issue or interest, just like an institutional field that involves a "community of organizations that partakes of a common meaning system” (Scott 1995: 56). 
There is a proliferation of international regimes, not only with regard to the environment (Young and Demko 1997) but also to trade and investment (Murphy 1998) and economics and finance (Neumayer 2001). With such a wide range of applicability, it is not surprising that there is no one overarching version of regime theory but different strands, which can be mapped onto different approaches in institutional theory.

\section{Three Schools of Thought}

Based on the assumptions they make about actors and their motivations, the principal schools of thought are: interest-based (neo-liberalist), power-based (realist), and knowledgebased (cognitivist) (Hasenclever et al. 2000). Interest-based theories, like institutional economics, regard self-interest as the basis of cooperation among actors. Power-based perspectives share with old institutionalism an emphasis on power differentials as determinants of regime effectiveness. The cognitivist theories are the most 'institution-centric' (Wendt and Duvall 1989) and, like neo-institutionalism, focus on institutionally constructed belief systems.

Interest-based theories represent the mainstream approach in analyzing international institutions (Hasenclever et al. 2000). Explanations for resolving problems of multiple equilibria in game-theoretic terminology involve motivating calculating actors engaged in the pursuit of self-interest through the creation of appropriate incentives and norms of reciprocity, such as the mutual dismantling of protective tariffs in international trade (Barrett 2003). In power-based arguments, powerful actors create hegemonic stability through a unipolar concentration of power in a particular issue area (Keohane 1984). A recent example is that of the USA using its influence within the international community to induce other countries to join the war in Iraq. Finally, the cognitivist school (Wendt and Duvall 1989) explains international cooperation on the basis of institutions: collective identities, beliefs, and norms 
that a community develops over time. Thus, if internationally agreed norms and rules are seen to be legitimate and fair, they exert a "compliance pull of their own” (Franck 1990: 49) through norms of reciprocity (Keohane 1984). For instance, decolonization was not just about the balance of power or economic incentives but also about the change in beliefs about what constituted legitimate rule (Jackson 1993).

In totality, these three schools of thought provide complementary explanations of cooperation among actors. Such cooperation comprises several stages. In the first instance, cooperation is required to overcome the start-up, free-ride, and apathy problems, and allow the emergence of new regimes. Subsequently, cooperation must continue for the sustenance of regimes and this involves costs associated with monitoring to prevent defection (Axelrod and Keohane 1986). While institutional theorists attribute actors' ability to induce cooperation primarily through the use of social and political skills, regime theorists have identified additional mechanisms that induce cooperation at a collective level. These include setting an appropriate 'game' structure, linking issues, making side payments, building capacity, and assessing performance. Through a review and synthesis of these regime-theoretic change mechanisms, in conjunction with traditional accounts of institutional entrepreneurship and interorganizational collaboration in the organizational literature, we now develop a framework for institutional entrepreneurship in collective action domains.

\section{Drivers of Collective Institutional Entrepreneurship}

While collective institutional change can be triggered by external shocks or "jolts" (Hoffman 1999; Meyer et al. 1990) such as scientific breakthroughs, natural catastrophes, regulatory upheavals, or technological discontinuities that raise actors' sensitivity towards an issue and galvanize actors into cooperating, the focus here is on endogenous drivers or 
internal factors that explain how numerous dispersed actors overcome the collective action paradox to attain and sustain cooperation in complex domains. We discuss them in turn.

\section{Manipulating Power Configuration}

This means skillfully reconfiguring power in a particular domain to achieve a power concentration that reduces the diversity of opinion and spurs collective institutional entrepreneurship. While old institutionalists highlighted how power struggles and conflicts of interests create change (Hirsch and Lounsbury 1997), neo-institutionalists, especially those focusing on non-isomorphic institutional change, also consider power and control of resources to be a central aspect of collaboration and change (Greenwood and Hinings 1996; Clegg et al. 2006). Substantial power differences among participants in 'volatile domains' can inhibit the formation of collaborative relationships (Hardy and Phillips 1998), although the dominance of some over others can also provide the stage for collaboration (Huxham and Vangen 2005). Power differences between actors can be used by the more powerful to dictate the rules of the game and induce cooperation; in the absence of a powerful 'storekeeper' or hegemon, others (free-riders) would be unwilling to 'mind the store' and regime effectiveness would erode (Krasner 1983).

\section{Creating Common Ground}

This represents a repertoire of bridging tactics that socially skilled actors use to induce cooperation from both allies and adversaries (Fligstein 1997). These include: 'framing' (Benford and Snow 2000), which induces cooperation by appealing to mutual identity and interests (Ansell 1998); setting an agenda which others believe to be in their own interests (Lukes 1974); expressing tangible and task-oriented, rather than elusive goals (Huxham and 
Vangen 2005); and building ‘cognitive legitimation’ by spreading public knowledge about an issue to make it more familiar and amenable to acceptance (Aldrich and Fiol 1994).

The cognitivist school in regime theory resonates with the institutional argument that actors operate in harmony with the consensual norms and values of the society into which they are socialized. Instead of leveraging incentives or power, actors create common ground and coincident interpretations by promoting overriding values that all accept (Levy and Egan 2003), heightening actor awareness of their mutual interdependence and paving the way for a collaborative strategy of engagement.

\section{Mobilizing Bandwagons}

This refers to actors enrolling large numbers of other participants to generate diffusion processes in favor of the collective issue at stake (Abrahamson and Rosenkopf 1993; Hardy and Phillips 1998). The momentum creates isomorphic pressures for a critical mass of adoption (cooperation) and allows for the emergence of new institutions. Indeed, collective action can only be successful when institutional entrepreneurs are able to enroll a large majority of actors through the process of 'intéressement' or alliance building by including like-minded actors (Callon 1991).

\section{Devising Appropriate Incentive Structures}

This consists of designing institutional arrangements that encourage cooperation by reducing transaction costs - a common argument in institutional economics (North 1990). Wider support may also be garnered by creating appropriate incentive structures and raising awareness of non-compliance costs (Barrett 2003). As neo-institutionalists acknowledge, such structures are typically conceived or stimulated by 'calculating' and 'interest-seeking' 
institutional entrepreneurs (Greenwood and Suddaby 2006) who enforce cooperation through both material and non-material incentives (Knoke 1988).

Regime theory adds insights about effective incentives such as the design of an appropriate game structure that enhances compliance and deters free-riding. The issue under contention can be made self-enforcing (Barrett 2003) or be turned from a 'public good', accessible to all, into a 'club good' with exclusive benefits for club members that commit themselves to the institutional arrangements (Neumayer 2001). Actors can also build and sustain cooperation by reducing the costs associated with negotiating, monitoring, and enforcing agreements (Keohane 1984). Forums can be created that provide information about the relative distribution of gain from compliance and which progressively build trust among participants.

Another regime-theoretical instrument is issue linkage (Sebenius 1983), where different problems with positive interdependence are clustered to encourage and ensure cooperation (Levy et al. 1993; Milner 1992). Since regimes do not exist in a societal vacuum, the repercussions of agreement violation may extend beyond the focal issue (Axelrod 1984), as in the attempts by OPEC members to link oil discussions with political issues. Issue linkage widens the scope for mutually beneficial exchanges, thus opening up more possible solutions for 'deadlocked problems' and facilitating effective retaliation against defectors or cheaters. Furthermore, it creates leverage by gaining actors' commitment on low-priority issues and then getting them to cooperate on high-priority issues (Susskind 1994). A related mechanism is side payments, such as offering technological assistance in exchange for non-proliferation agreements. Creating effective incentives can thus be a powerful driver of collective institutional entrepreneurship. 


\section{Applying Ethical Guidelines}

This means motivating actors to cooperate by invoking ethical factors such as sense of fairness, equity, and altruism. While institutional theory typically explains behavior as influenced by social norms, in many instances people act not because of normative conformity (Knoke and Wright-Isak 1982) but because they perceive the act to be the 'right' thing to do (Wendt 2001). Such moral legitimacy reflects a positive normative evaluation of activities based on existing value systems (Aldrich and Fiol 1994) and is 'sociotropic': “it rests not on judgments about whether a given activity benefits the evaluator", but rather on judgments about whether the activity effectively promotes societal welfare (Suchman 1995: 579). Regime theory explains how perceptions of fairness, ethical probity, and a shared aversion for negative outcomes can create compliance (Fireman and Gamson 1979).

\section{Using Implementation Mechanisms}

This refers to employing specific instruments to implement joint agreements. While institutional theory acknowledges that collective change can only be sustained if effectively implemented (Greenwood et al. 2002), it does not offer specific insights into implementation mechanisms. Here regime theory offers a number of guidelines. Implementation capacity can be built through information transfer, research grants, technical assistance, training, and management expertise to resource-constrained actors. Furthermore, periodic and timely assessments of the progress through review mechanisms (Young and Demko 1997) and noncompliance procedures (Wettestad 1999) ensure continued cooperation.

All the above drivers can be leveraged in acts of collective institutional entrepreneurship to engender and sustain cooperation in collective action domains. For analytical reasons, we separated the various forces at play into six main drivers, but 
understandably it is their confluence that brings about collective change through collaboration. Next, we apply our framework to global climate policy, in particular the entryinto-force of the Kyoto Protocol, a recent but very influential global institution that addresses a major collective-action problem. The emergence of this new global regulatory institution was not triggered by any external shock or sudden power shifts; rather, near-unanimous adoption was achieved through collaborative breakthroughs. We therefore use this global institution to illustrate the drivers in our framework.

\section{ILLUSTRATION: THE EMERGENCE OF GLOBAL CLIMATE POLICY}

We selected global climate policy to illustrate our framework since it has evolved over two decades from a 'non-issue' to a major institutional field which faces the collective action dilemma. Our analytical focus was the nation state, underrepresented in the organizational literature in comparison with the corporation (Levy and Egan 2003; Kolk and Pinkse 2005). The process leading to the conclusion of the Kyoto Protocol has been extensively described in the literature. In particular, we drew on Bartsch et al. (2000), Grubb et al. (1999), and Oberthür and Ott (1999), who provide excellent historical overviews, as well as a range of other secondary sources, complemented by in-depth interviews with 30 experts in Europe and North America who had been involved in different roles (as negotiators, lobbyists, and observers) at different stages of the evolution of global climate policy and who represented the spectrum of different perspectives (national and supranational authorities, nongovernmental organizations, business associations, and scientists). The interview transcripts and notes, totaling 230 pages, were analyzed with the qualitative software package Atlas/ti to systematically construct a coherent narrative. 


\section{The Climate Change Problem}

A number of gases in the earth's atmosphere, especially carbon dioxide, capture solar radiation that bounces from the earth. This heat retention or greenhouse effect causes a gradual warming of the earth's atmosphere. It has both natural and human-induced causes. A large part of the human impact stems from the combustion of fossil fuels, which releases greenhouse gases (GHGs) that can lead to both progressive warming and increased occurrence of extreme weather events (Oberthür and Ott 1999). Probable consequences include the flooding or desertification of large areas, the disappearance of lowly situated islands, the melting of ice caps, the disappearance of many living species, and reduced economic growth (Stern 2006). The ensuing damage can be enormous. The material damage from extreme weather events has risen tenfold over the last four decades, and is expected to continue mounting due to cumulative, time-lagged effects (Holdren 2003; IPCC 2001).

Mitigating the greenhouse effect is a collective action dilemma as it would require major changes in the production and consumption patterns of many nations. Getting these nation states to cooperate, however, poses a significant challenge. Firstly, most of them depend heavily on fossil fuels, as suppliers or consumers. Secondly, climate-change mitigation involves important externalities. While GHG emissions from all over the planet contribute to the global problem, parties taking corrective action enjoy only a small share of the benefits. Furthermore, important time lags separate the generations (not) taking action from those bearing the consequences of (in)action. Climate change is thus a major collective-action problem (Barrett 2003).

\section{The Institutionalization of Global Climate Policy}

The Intergovernmental Panel on Climate Change (IPCC), created in 1988, made the first major attempt to address climate change by increasing scientific knowledge of this complex 
and controversial issue. Based on IPCC's initial results, leaders of 188 countries accepted the UN Framework Convention on Climate Change (UNFCCC) at the Rio Earth Summit in 1992, which still constitutes the formal basis of all global climate policy (Oberthür and Ott 1999). It aims at the stabilization of atmospheric GHGs through the principle of common but differentiated responsibilities, encouraging developed countries to take the lead. The Convention operates through a Conference of the Parties (COP) to annually discuss progress and plans among nation states, a permanent Secretariat to deal with operational aspects, two Subsidiary Bodies to provide technical assistance, and a Global Environment Facility to financially support developing countries.

After the IPCC’s 1995 report, indicating ‘a discernible human influence on global climate change', and two preparatory COP meetings, the COP session in Kyoto in 1997 led to the unanimously accepted 'Kyoto Protocol’ (Grubb et al. 1999). The Protocol stipulated that the overall GHG emissions of industrialized countries ('Annex I Parties') had to be reduced by 5.2\% over the period 2008-2012 (the 'first commitment period') in comparison with the base year 1990. The target concerns the net greenhouse impact: the emissions of a basket of six GHGs minus the absorption of these gases by 'sinks' (mainly forests). Developed nation states committed themselves to individualized targets, ranging from an $8 \%$ reduction to a $10 \%$ increase. No emission ceilings were formulated for developing countries.

The Kyoto Protocol does not prescribe policies and measures (PAMs) but introduces a series of flexible implementation mechanisms (Bartsch et al. 2000; Grubb et al. 1999): emission trading (countries with unexploited emission room or 'hot air' selling this surplus to countries exceeding their emission ceilings), joint implementation (JI, making emissionreducing investments in other industrialized countries), and the clean development mechanism (CDM, similar to JI but concerning investments in developing countries). The Protocol allows for excess emissions in a particular year to be compensated in subsequent years and for saving 
unused assigned quantities for future periods ('banking'). Non-complying parties must assume a 30\% reduction surcharge in the next commitment period. The Kyoto Protocol has no significant means to penalize non-compliance.

Subsequent COP sessions led to further elaboration of the Kyoto Protocol. The European Union (EU) implemented the Protocol through legislation, imposing emission 'caps' on large companies in targeted sectors and introducing an emission-trading system (Cass 2005). However, Kyoto’s entry-into-force was under threat because the United States (US), representing a third of all Annex-I emissions, had rejected the Protocol in 2001. To clear the 'double hurdle' of getting on board at least 55\% of all countries representing no less than 55\% of all Annex-I emissions, it became imperative that Russia, a major emissions producer, also ratify the treaty. After protracted negotiations, Russia complied and the Protocol entered into force in 2005, implying that 156 countries representing 62\% of all Annex-I emissions had ratified, or otherwise accepted, the Kyoto Protocol (UNFCCC 2005). The US then signed an alternative, 'complementary' agreement with Australia (which had not ratified the Kyoto Protocol either), China, India, and South Korea to mitigate climate change through economic transactions in 'clean' energy technology. Since then, annual COP meetings have focused on new, increasing commitments for states after 2012, when the first commitment period ends. The European Commission launched, early in 2007, an initiative calling for a 20\% reduction in EU emissions by 2020 (as compared with 8\% by 2012). Formal global climate policy has thus become increasingly institutionalized (Depledge 2006; Hovi et al. 2003).

\section{Collective Institutional Entrepreneurship in Global Climate Policy}

In the theoretical framework, we identified six drivers that actors employ to spur and sustain collective change in an institutional field. Here, we discuss the relation of each 
endogenous driver to collective institutional entrepreneurship in the field of global climate policy.

\section{Manipulating Power Configuration}

At the outset, some 200 sovereign nation states became involved in the global climate policy process. The large number of actors and the diversity of their views and motives engendered enormous complexity. Furthermore, the representatives of national climate-policy delegations, especially those of Europe and North America, often faced conflicting domestic interests. The US and OPEC countries were sympathetic with the conservative business lobby and supported their opposition to measures that would restrict their economic activities (Levy and Egan 2003). In contrast, EU member states and developing countries sided with environmental NGOs, who argued that GHG-intensive activities of 'heavy emitters' had to be stringently regulated (Oberthür and Ott 1999).

After protracted negotiation (see below), three major blocks emerged: the EU, then consisting of 15 member states; the G77, representing over 100 developing countries; and the JUSSCANNZ coalition, made up of Japan, the US, Switzerland, Canada, Australia, Norway, and New Zealand (Grubb et al. 1999). According to a Kyoto negotiator, "One was [negotiating] not as an individual party, but as part of a block.” A UN official added: “[T]he three major economic powers [the US, Japan, and the EU] were the main guiding forces. Obviously, the group of developing countries was also important.” Three major clusters emerged among almost 200 individual actors that concentrated power in the hands of a few. Several interviewees stressed that as nation states sought to manipulate power configuration by allying with other states to increase their bargaining power, the number of actors (and consequently the diversity of opinions) was dramatically reduced. This greatly facilitated the realization of consensus among diverse actors during the final Kyoto negotiations. 


\section{Creating Common Ground}

Another important driver for building consensus was to create a shared vision. The large group of international experts in the IPCC contributed to creating a shared and 'objective' understanding of climate change through increased scientific knowledge about the phenomenon. 'Hard' scientific evidence helped overcome political bickering and humaninduced climate change came to be widely accepted as a 'fact' (Oberthür and Ott 1999). As argued by an NGO observer, "Because the science became so much stronger, there was a scientific consensus that was endorsed by the majority of the governments of the planet.” (Subsequent to the entry-into-force of the Kyoto Protocol, consensus among public policymakers appears to have been further increased by an authoritative economic report (Stern 2006), a political documentary with former US Vice-President Al Gore (Guggenheim 2006), and 'stronger' scientific evidence (IPCC 2007) on the causes and consequences of climate change.)

Despite widely divergent viewpoints, the negotiations led to the emergence of influential coalitions (Grubb et al. 1999; Oberthür and Ott 1999). Realizing that they were individually too weak to significantly influence the outcome, nation states allied with like-minded parties. EU member states shared high concern about climate issues, while southern European states did not want to compromise their economic growth. After intense internal negotiations, facilitated by scientific calculations of 'reasonable' individual targets, the EU finally came to a 'Bubble' agreement with one overall but internally differentiated target, ranging from -28\% to $+27 \%$ (Grubb et al. 1999). This agreement enabled the EU to speak with one voice and support stringent PAMs. According to a Kyoto observer, "If the EU had not come with a good, coherent story about how to address the burden sharing, other parties would have 
completely divided it. The calculations established a basis for political coordination within the EU.”

The G77 countries faced a different challenge. The stakes of the small-island states, who were threatened by disappearance, sharply contrasted with those of OPEC countries, whose principal sources of income were under threat. The G77 members tended to abstain from any commitments, arguing that it was the industrialized states that needed to 'clean up the mess' they had themselves created. The G77 had created a structure with a revolving chairmanship to protect the common interests of all members and well-prepared negotiators from large countries such as China and Brazil vigorously defended its position.

The JUSSCANNZ coalition consisted of industrialized countries that wished to avoid stringent PAMS for different reasons. Japan was already an energy-efficient economy. The US expressed concern about constraining its economic growth. Sweden had just switched from nuclear to conventional power sources. Canada had considerable stakes in the production of fossil fuels. And Norway, Switzerland, and New Zealand had already switched to the higher use of natural energy sources. The unusual JUSSCANNZ coalition, dominated by the US and Japan, thus tried to block constraining regulation. Many interviewees stressed that when the enormous diversity of views and interests was reduced to three major negotiation blocks, the largest common denominator was obtained: the Kyoto Protocol specified binding targets (for reducing emissions) for industrialized countries, but with high flexibility as to their achievement.

Several individuals and delegations facilitated consensus-building by employing their social skills (Gupta 2001). Environmental-Ministry officials of the Netherlands, chairing the EU in the first half of 1997, succeeded in bridging divergent stances through intensive consultation with EU member states. People within NGOs and academia also made relentless efforts to ensure persistent media coverage and influence on negotiation delegations, 
especially those from developing countries. During the negotiations in Kyoto, chairman Raúl Estrada-Oyuela's skills and determination to bridge divergent positions, ignore objections, highlight commonalities, and hammer out an agreement were considered by several observers as indispensable to the Protocol's conclusion. For example, a former G77 adviser argued: "Estrada was a terrific manager. He managed to not hear certain complaints, not to pay attention to them. He heard a consensus and so he said: 'We're going forward.' I think he was brilliant.” Subsequently, several European politicians took significant initiatives. For instance, the Dutch Environment Minister Jan Pronk helped obtain consensus on critical issues during subsequent COP meetings, while the British Prime Minister Tony Blair made global climate policy a top priority of his G8 chairmanship. Different actors thus created common ground: scientists clarified the causes and consequences of climate change, national negotiators sought and found common objectives with other states, and the chairman in Kyoto united divergent parties.

\section{Mobilizing Bandwagons}

Peer pressure and media exposure also helped in the emergence of a consensus. The development of a global climate policy faced frequent deadlocks, even during the Kyoto meeting. While many countries threatened to withdraw from the process, none did. The media and NGOs continuously covered the negotiations (Oberthür and Ott 1999). Multiple interviewees argued that this deterred withdrawals as no country wanted to be seen as subverting the process in the glare of the world media. Therefore, when the EU campaigned for a unanimous agreement, all countries followed suit, including skeptics such as the US and Japan. A former Kyoto negotiator: "[T]here was this feeling that the whole world was watching and that the negotiations could consequently not fail.” The media and NGOs thus 
mobilized collaborative bandwagons that enabled enrolling diverse states for a common cause.

\section{Devising Appropriate Incentive Structures}

The binding individual targets for industrialized countries over the period 2008-2012, together with the 30\% emission surcharge for non-compliance, are more concrete incentives than most other multilateral agreements among nations. At the same time, the average emission reduction of $5.2 \%$ is at best modest and meant only for industrialized countries (Grubb et al. 1999). Interviewees argued that these countries could circumvent domestic action by complying abroad, buying off their commitments, and eschewing ambitious targets for the yet-undefined post-2012 period.

In contrast, side payments and issue linkage were successful instruments. The developing countries disliked the idea that industrialized countries could simply comply abroad, rather than 'clean up their own household' (Oberthür and Ott 1999). This opposition subsided when industrialized countries agreed to pay for the (additional) costs of CDM investments and provide free technology transfers to developing countries. The Kyoto Protocol would also not have emerged without ratification from Russia, which held a pivotal position after the US withdrawal in order to meet the double 55\% threshold. A major reason why Russia finally did ratify was the EU's pledge to support Russia in becoming a member of the World Trade Organization. A newspaper article read, "During the [May 2004] Summit in Moscow, Russia and the EU reached an agreement on the Russian accession to the World Trade Organization (WTO). While both parties formally deny a linkage between both negotiations, [Russia's President, Mr.] Putin said that European concessions in the field of bilateral trade relations had stimulated 'a positive attitude towards ratification of [the] Kyoto [Protocol]'.” In short, 
national negotiators of the Kyoto Protocol and the EU successfully leveraged incentive instruments such as side payments and issue linkage to enroll a large number of actors.

\section{Applying Ethical Guidelines}

Developed nation states accepted individualized binding targets and the exemption of developing countries from targets based on the perceived fairness of the UNFCCC principle of common but differentiated responsibilities. Likewise, the internal EU agreement stipulated that each member state would assume a 'fair share' of the burden, based on objective calculations (Phylipsen et al. 1998). According to a Kyoto negotiator, "[W]ithin the EU, solidarity was a crucial factor. Despite important ignorance (about what constituted a fair target), one was prepared to embrace the so-called 'Bubble' to enable negotiations.”

Several interviewees highlighted that most nation states also had a joint ethical interest: a common and shared aversion to the problem that climate change could bring. With incremental but mounting scientific evidence, most countries began to recognize the moral responsibility of protecting future generations from its adverse consequences. Ethical guidelines such as fairness and shared aversion thus drove national negotiators to commit their countries towards mitigating climate change and to encourage others to follow suit.

\section{Using Implementation Mechanisms}

The Kyoto Protocol assigned several implementation mechanisms to sustain cooperation. Apart from the GHG absorbing sinks, three innovative policy instruments were introduced to implement commitments: emission trading, JI, and CDM (Grubb et al. 1999). These flexible mechanisms made it considerably easier for many parties with binding commitments to meet their targets. As a UN official argued, "One of the strengths is that, for the first time, 
international economic instruments are part of the treaty. Because of these [implementation] instruments, (...) the Kyoto Protocol has a bigger impact than other treaties in the past.”

Apart from the compliance mechanisms, all ratifying nation states consented to annual assessments of their GHG emission levels, enabling the global community to track actual performances and compare them to the agreed targets. Since many (developing) countries did not have the technical and financial capacities to accurately assess their emission levels, know-how and funds were provided to make sure they could participate (Bartsch et al. 2000). The UNFCCC Secretariat and other bodies supported and coordinated this process. National negotiators thus conceived and successfully applied implementation mechanisms such as innovative policy instruments, performance assessment, and capacity building to obtain and maintain the commitment of states to a global climate policy.

\section{DISCUSSION AND CONCLUSION}

While institutional theory has taken huge strides towards addressing the agency-structure paradox, there are few studies of collective institutional change where numerous dispersed actors need to overcome collective action dilemmas. To understand institutional change in the presence of fragmented interests, we drew on critical insights from regime theory, a research tradition in international relations where scholars have long studied the existence of considerable international cooperation among autonomous states through intergovernmental arrangements in the absence of a supranational authority. While the regime approach is largely state-centric, international decisions are also made and implemented by non-state actors (Kahn and Zald 1990). Insights from organizational theory thus have significant potential to inform international relations and revitalize regime analysis. On the other hand, regime-theoretic insights, though not frequently employed (Louis and Gray 1992), are just as 
relevant for organizational scholars, in particular to understand the notion of collective institutional entrepreneurship.

After reviewing and synthesizing institutional and regime theories, we constructed a conceptual framework of six drivers of collective institutional entrepreneurship. One driver, mobilizing bandwagons, was derived directly from institutional theory (Abrahamson and Rosenkopf 1993). Others, despite having origins in institutional theory, contain important differences. For instance, while common ground creation is similar to leveraging, it is the consequence of the collective efforts of numerous actors, rather than the skills of one or a few key institutional entrepreneurs (Greenwood and Suddaby 2006; Lawrence and Suddaby 2006). Consider the business world's development of 'private' regimes for facilitating commercial operations (Rittberger 1995), such as the chemical industry’s Responsible Care program to address environmental issues (Hoffman 1999) that required 'institutional work' from a broad category of actors. Similarly, while both old institutionalism and neoinstitutionalism consider power and control of resources to be a central aspect of collaboration and change (Greenwood and Hinings 1996), there are few discussions about the regimetheoretic argument of how power concentration enables cooperation. Finally, while institutional theorists recognize that behavior is influenced by social norms (Suchman 1995), there is far less emphasis on explaining actions that are driven by ethical motives such as altruism and a sense of fairness, rather than normative conformity (Wendt 2001).

Even the drivers with origins in regime theory are certainly not alien to institutional theorists, but have not been highlighted or labeled as such in empirical descriptions of institutional entrepreneurship or change in the literature. For instance, the use of bargaining and deal-making can be considered incentive structures through which institutional entrepreneurs manipulate the support of stakeholders by conveying the political consequences of (not) supporting change in emerging fields (Maguire et al. 2004). Likewise, institutional 
theorists acknowledge that effective implementation and maintenance of the institutional order through 'policing' - enforcement, auditing, and monitoring (Lawrence and Suddaby 2006) - are essential for long-term institutional survival, even if the maintenance of organizational fields has received significantly less attention than their creation (Scott 2001). For instance, Guler et al.’s (2002) study of ISO 9000 quality certification for firms documents the importance of regular monitoring to maintain compliance with standard institutionalized practices, but does not specify mechanisms or guidelines to sustain an emerging order. Regime theory, on the other hand, provides several mechanisms to ensure compliance and to sanction underperforming actors (Wettestad 1999).

By exploring the conceptual connections between institutional and regime theories, we have provided a multi-faceted framework for explaining collective institutional entrepreneurship. Firstly, we have enriched institutional theory with insights from regime theory, showing how collective institutional entrepreneurs can create agency among actors in the face of collective inaction. Secondly, we have developed an analytical framework that can be used in the 'non-institutional' literature addressing interorganizational collaboration. Thirdly, our explanation for collective institutional entrepreneurship and change is powerful since it views embedded actors as responding to both a 'logic of consequentiality' and a 'logic of appropriateness’ (March and Olsen 1989). Indeed, sociological theories can gain from 'treading' into the rational choice terrain (Zajac and Westphal 2004) and we engage institutionalists by demonstrating that such conceptions offer a more comprehensive explanation of agency in collective action domains. Finally, our analysis has important implications for practice, where agents often face the double paradox of institutionalization in collective action areas.

Practitioners should be conscious of, and draw on, the panoply of drivers of collective institutional entrepreneurship that operate in confluence, both concurrently and sequentially. 
Rather than deadlocking collective change efforts and fomenting 'turf battles' by targeting a subset of stakeholders with a few, predetermined change instruments, collective institutional entrepreneurs should explore the best possible (combination of) instruments to engage divergent institutional actors at different points in time. For example, entrepreneurs may first appeal to relatively like-minded actors through ethical inducements and common ground exploration to generate a critical mass, then mobilize reluctant actors through appropriate incentives, timely information dissemination, empathy with divergent viewpoints, devising arrangements which others perceive as fair, and 'shaming' the defectors into fulfilling responsibilities, and finally build capacity and regularly perform assessments to sustain and implement change. Since agency is dispersed, it is critical for collective institutional entrepreneurs to engage credible others who fulfill complementary roles in the institutional work required for undertaking and maintaining collective action.

While much theorizing remains to be done in this emerging view of collective institutional entrepreneurship, we believe our study is an important step forward. The relative importance of various drivers in our framework and their interactions should be tested on a range of collective action issues. At the discursive level, a study of the language actors adopt to bring others into the fold would reveal important dynamics of collective institutional entrepreneurship. Scholars should also focus on failed efforts to collaborate and change, as many conflicts remain unresolved and intractable. Finally, a more fine-grained analysis of differences in individual attributes of participants such as identities, cultural backgrounds, and collaborative experience would be important because actors may differ in their propensity to cooperate (Weber et al. 2004), resulting in different 'thresholds' for joining a collective cause (Granovetter 1978). It is indeed the micro-level interplay of interests, power, and cognition that trickles up to agency at the collective level. Such a micro-level analysis may also reveal 
covert purposes of collaboration and the extent to which cooperation may be cooptation or extended for ceremonial reasons. 


\section{REFERENCES}

Abrahamson, E., and L. Rosenkopf

1993 'Institutional and competitive bandwagons: Using mathematical modeling as a tool to explore innovation diffusion'. Academy of Management Review 18: 487-517.

Aldrich, H., and M. Fiol

1994 'Fools rush in? The institutional context of industry creation'. Academy of Management Review 19: 645-670.

Ansell, C.

1998 'Symbolic networks'. American Journal of Sociology 103: 359-390.

Axelrod, R.

1984 The evolution of cooperation. New York: Basic Books.

Axelrod, R., and R. Keohane

1986 'Achieving cooperation under anarchy: Strategies and institutions' in Cooperation under anarchy. K. Oye (ed.). Princeton: Princeton University Press.

Barley, S., and P. Tolbert

1997 'Institutionalization and structuration: Studying the links between action and institution’. Organization Studies 18: 93-117.

Barrett, S.

2003 Environment \& statecraft: The strategy of environmental treaty-making. Oxford: Oxford University Press.

Bartsch, U., B. Müller, and A. Aaheim

2000 Fossil fuels in a changing climate: Impacts of the Kyoto Protocol and developing country participation. Oxford: Oxford University Press.

Beckert, J.

1999 'Agency, entrepreneurs, and institutional change: The role of strategic choice and institutionalized practices in organizations. Organization Studies 20: 777-799.

Benford, R., and D. Snow

2000 'Framing processes and social movements: An overview and assessment'. Annual Review of Sociology 26: 611-39

Callon, $\mathrm{M}$.

1991 'Techno-economic networks and irreversibility' in A sociology of monsters: Essays on power, the technology and domination. J. Law (ed.). London: Routledge.

Cass, L.

2005 'Norm entrapment and preference change: The evolution of the European Union position on international emissions trading'. Global Environmental Politics 5/2: 38-60. 
Chrislip, D., and C. Larson

1994 Collaborative leadership: How citizens and civic leaders can make a difference. San Francisco: Jossey-Bass.

Clegg, S, D. Courpasson, and N. Phillips

2006 Power and organizations. London: Sage.

Dacin, T., J. Goodstein, and R. Scott

2002 'Institutional theory and institutional change: Introduction to the special research forum’. Academy of Management Journal 45/1: 45-56.

Depledge, $\mathrm{J}$.

2006 'The opposite of learning: Ossification in the climate change regime'. Global Environmental Politics 6/1: 1-22.

DiMaggio, P.

1988 'Interest and agency in institutional theory' in Institutional patterns and organizations: Culture and environment. L. Zucker (ed.). Cambridge: Ballinger.

DiMaggio, P., and W. Powell

1991. 'Introduction' in The new institutionalism in organizational analysis. W. Powell and P. DiMaggio (eds). Chicago: University of Chicago Press.

Dorado, S.

2005 'Institutional entrepreneurship, partaking, and convening'. Organization Studies 26/3: 385-414.

Emery, F., and E. Trist

1965 'The causal texture of organizational environments'. Human Relations 1: 21-35.

Fireman, B., and W. Gamson

1979 'Utilitarian logic in the resource mobilization perspective' in The dynamics of social movements: Resource mobilization, social control, and tactics. M. Zald and J. McCarthy (eds). Cambridge: Winthrop.

Fligstein, N.

1997 'Social skill and institutional theory'. The American Behavioral Scientist 40/4: 397405.

Franck, T.

1990 The power of legitimacy among nations. New York: Oxford University Press.

Garud, R., S. Jain, and A. Kumaraswamy

2002 'Institutional entrepreneurship in the sponsorship of common technological standards: The case of Sun Microsystems and Java'. Academy of Management Journal 45/1: 196214.

Granovetter, M.

1978 'Threshold models of collective behavior'. American Journal of Sociology 83/6: 14201443. 
Gray, B.

1989 Collaborating: Finding common ground for multiparty problems. San Francisco: Jossey-Bass.

Greenwood, R., and C. Hinings

1996 'Understanding radical organizational change: Bringing together the old and the new institutionalism'. Academy of Management Review 21/4: 1022-1054.

Greenwood R., and R. Suddaby

2006 'Institutional entrepreneurship and the dynamics of field transformation'. Academy of Management Journal 49/1: 27-48.

Greenwood, R., R. Suddaby, and C. Hinings

2002 'The role of professional associations in institutional change'. Academy of Management Journal 45: 58-80.

Grubb, M., C. Vrolijk, and D. Brack

1999 The Kyoto Protocol: A guide and assessment. London: Royal Institute of International Affairs and Earth Scan.

Guggenheim, D.

2006 An inconvenient truth. Paramount Classics.

Guler, I., M. Guillen, and J. MacPherson

2002 'Global competition, institutions and the diffusion of organizational practices: The international spread of ISO 9000 quality certificates'. Administrative Science Quarterly 47: 207-233.

Gupta, J.

2001 Our simmering planet: What to do about global warming? London: Zed Books.

Hardy, C., and N. Phillips

1998 'Strategies of engagement: Lessons from the critical examination of collaboration and conflict in inter-organizational domains'. Organization Science 9: 217-230.

Hasenclever, A., P. Mayer, and V. Rittberger

1997 Theories of international regimes. Cambridge: Cambridge University Press.

Hasenclever, A., P. Mayer, and V. Rittberger

2000 'Integrating Theories of International Regimes'. Review of International Studies 26/1: 3-33.

Heckathorn, D.

1996 'The dynamics and dilemmas of collective action'. American Sociological Review 61/2: 250-277.

Hirsch, P., and M. Lounsbury

1997 'Ending the family quarrel: Toward a reconciliation of "old" and "new" institutionalisms'. American Behavioral Scientist 40: 406-418. 
Hoffman, A.

1999 'Institutional evolution and change: Environmentalism and the U.S. chemical industry. Academy of Management Journal 42: 351-371.

Holdren, J.

2003 Risks from global climate change: What do we know? What should we do? Presentation at the Institutional Investors' Summit on Climate Risk. 21 November. New York: United Nations.

Hovi, J., T. Skodvin, and S. Andresen

2003 'The persistence of the Kyoto Protocol: Why other Annex I countries move on without the United States'. Global Environmental Politics 3/4: 1-23.

Huxham, C., and S. Vangen

2000 'Leadership in the shaping and implementation of collaboration agendas: How things happen in a (not quite) joined-up world'. Academy of Management Journal 43/6: 1159-1175.

Huxham, C. and S. Vangen.

2005 Managing to collaborate: The theory and practice of collaborative advantage. London: Routledge.

IPCC

2001 'Third assessment report of the Intergovernmental Panel on Climate Change'. http://www.ipcc.ch/pub/un/syreng/spm.pdf.

IPCC

2007 'Contribution of working group I to the fourth assessment report of the Intergovernmental Panel on Climate Change. http://www.ipcc.ch/SPM2feb07.pdf.

Jackson, R.

1993 'The weight of ideas in decolonization: Normative change in international relations' in Ideas and foreign policy. J. Goldstein and R. Keohane (eds). Ithaca: Cornell University Press.

Jepperson, R.L.

1991 'Institutions, institutional effects, and institutionalism', in The new institutionalism in organizational analysis. W. Powell and P. DiMaggio (eds.). Chicago: University of Chicago Press.

Kahn, R., and M. Zald (eds)

1990 Organizations and Nation-States. San Francisco: Jossey-Bass.

Keohane, R.

1984 After hegemony: Cooperation and discord in world political economy. Princeton: Princeton University Press.

Knoke, D.

1988 'Incentives in collective action organizations'. American Sociological Review 53: 311329. 
Knoke, D., and C. Wright-Isak

1982 'Individual motives and organizational incentive systems'. Research in the Sociology of Organizations 1: 209-254.

Kolk, A., and J. Pinkse

2005 'Business responses to climate change: Identifying emerging strategies'. California Management Review 47/3: 6-20.

Krasner, S. (ed.)

1983 International regimes. Ithaca: Cornell University Press.

Lawrence, T., and R. Suddaby

2006 'Institutions and institutional work' in Handbook of Organization Studies. S. Clegg et al. (eds). London: Sage.

Levy, D., and D. Egan

2003 'A neo-Gramscian approach to corporate political strategy: Conflict and accommodation in the climate change negotiations'. Journal of Management Studies 40/4: 803-829.

Levy, M., R. Keohane, and P. Haas

1993 'Improving the effectiveness of international environmental institutions' in Institutions for the earth: Sources of effective international environmental protection. P. Haas et al. Cambridge: MIT Press.

Lincoln, J., M. Gerlach, and C. Ahmadijan

1996 'Keiretsu networks and corporate performance in Japan'. American Sociological Review 61: 67-88.

Louis, M., and B. Gray

1992 'Organizations and nation-states (book review)'. Academy of Management Review 17/1: 148-151.

Lounsbury, M., and M. Ventresca

2002 'Social structure and organizations revisited'. Research in the sociology of organizations 19: 1-36. New York: JAI Press/Elsevier.

Lukes, S.

1974 Power: A radical view. London: Macmillan.

Maguire, S. and C. Hardy

2006 'The emergence of new global institutions: A discursive perspective.' Organization Studies 27/1:7-29.

Maguire, S., C. Hardy, and T. Lawrence

2004 'Institutional entrepreneurship in emerging fields: HIV/AIDS treatment advocacy in Canada'. Academy of Management Journal 75/5: 1-23.

March, J., and J. Olsen 
1989 Rediscovering institutions: The organizational basis of politics. New York: Free Press.

Marwell, G., and P. Oliver

1993 The critical mass in collective action: A micro-social theory. New York: Cambridge University Press.

Meyer, A., G. Brooks, and J. Goes

1990 'Environmental jolts and industry revolutions: Organizational responses to discontinuous change’. Strategic Management Journal 11: 93-110.

Milner, $\mathrm{H}$.

1992 'International theories of cooperation among nations: Strengths and weaknesses'. World Politics 44: 466-494.

Möllering, G

2007 Collective institutional entrepreneurship? The recursive interplay of action, networks and institutions in market constitution. Paper presented at the Conference "The institutional embeddedness of markets”. Max Planck Institute. Cologne. February.

Murphy, C.

1998 'Understanding IR: Understanding Gramsci.' Review of International Studies 24/3: 417-425.

Neumayer, E.

2001 'How regime theory and the economic theory of international environmental cooperation can learn from each other'. Global Environmental Politics 1/1: 122-147.

North, D.

1990 Institutions, institutional change and economic performance. Cambridge: Cambridge University Press.

Oberthür, S., and H. Ott

1999 The Kyoto Protocol: International climate policy for the $21^{\text {st }}$ century. Berlin: Springer Verlag.

Oliver, C.

1997 'Sustainable competitive advantage: Combining institutional and resource-based views’. Strategic Management Journal 18/October: 697-713.

Oliver, P.

1993 'Formal models of collective action'. Annual Review of Sociology 19: 271-300.

Olson, $\mathrm{M}$.

1965 The logic of collective action: Public goods and the theory of groups. Cambridge: Harvard University Press.

Phillips, N., T. Lawrence, and C. Hardy

2000 'Inter-organizational collaboration and the dynamics of institutional fields'. Journal of Management Studies 37/1: 23-43. 
Phylipsen, G., J. Bode, K. Blok, H. Merkus, and B. Metz

1998 'A Triptych sectoral approach to burden differentiation: GHG emissions in the European bubble’. Energy Policy 26/12: 929-943.

Rao, H., C. Morrill, and M. Zald

2000 'Power plays: How social movements and collective action create new organizational forms' in Research in Organizational Behavior 22. B. Staw and R. Sutton (eds). Amsterdam: JAI Press/ Elsevier.

Ring, P., and A. Van de Ven

1994 'Developmental processes of cooperative interorganizational relationships'. Academy of Management Review 19: 90-118.

Rittberger, V. (Ed.)

1995 Regime Theory and International Relations. Oxford: Oxford University Press.

Roberts, P. and R. Greenwood

1997 'Integrating transaction cost and institutional theories: Toward a constrainedefficiency framework for understanding organizational design adoption'. Academy of Management Review 22/2: 346-373.

Scott, R.

1995 Institutional effects on organizational structure and performance in institutions and organizations. Thousand Oaks: Sage.

Scott, R.

2001 Institutions and organizations. Thousand Oaks: Sage.

Sebenius, J.

1983 'Negotiation arithmetic: Adding and subtracting issues and parties'. International Organization 37/2: 281-316.

Selznick, P.

1949 TVA and the grassroots: A study of politics and organization. Berkeley: University of California Press.

Seo, M.-G., and D. Creed

2002 'Institutional contradictions, praxis, and institutional change: A dialectical perspective’. Academy of Management Review 27/2: 222-247.

Stern, N.

2006 Stern review: The economics of climate change. Report presented to the British Prime Minister. 30 October.

Suchman, M.

1995 'Managing legitimacy: Strategic and institutional approaches'. Academy of Management Review 20: 571-610.

Susskind, L. 
1994 Environmental diplomacy: Negotiating more effective global agreements. New York: Oxford University Press.

Trist, E.

1983 'Referent organizations and the development of interorganizational domains'. Human Relations 36/3: 247-268.

\section{UNFCCC}

2005 'Kyoto Protocol: Status of ratification'. http://unfccc.int/files/essential_background/ kyoto_protocol/application/pdf/kpstats.pdf. 19 September. Bonn: UNFCCC secretariat.

Van de Ven, A., and R. Garud

1993 'Innovation and industry emergence: The case of cochlear implants' in Research on technological innovation, management, and policy 5. R. Rosenbloom and $\mathrm{R}$. Burgelman (eds). Greenwich: JAI Press.

Volger, J.

2003 'Taking institutions seriously: How regime analysis can be relevant to environmental governance’. Global Environmental Politics 3/2: 25-39.

Weber, J., Kopelman, S., \& Messick, D.

2004 'A conceptual review of decision-making in social dilemmas: Applying a logic of appropriateness'. Personality and Social Psychology Review, 8(3): 281-307.

Wendt, A.

2001 'Driving with the rearview mirror: On the rational science of institutional design'. International Organization 55/4: 1019-1049.

Wendt, A., and R. Duvall

1989 'Institutions and international order' in Global changes and theoretical challenges: Approaches to the world politics for the 1990s. E.-O. Czempiel and J. Rosenau (eds). Lexington: Lexington Books.

Westley, F., and H. Vredenburg

1997 'Interorganizational collaboration and the preservation of biodiversity'. Organization Science 8/4: 381-403.

Wettestad, J.

1999 Designing effective environmental regimes: The key conditions. Cheltenham: Edward Elgar.

Young, O.

1989 'International regimes: An institutional perspective' in International cooperation: Building regimes for natural resources and the environment. O. Young (ed.). Ithaca: Cornell University Press.

Young, O., and G. Demko

1997 'Improving the effectiveness of international environmental governance systems' in Global environmental change and international governance. O. Young et al. (eds). Hanover: Dartmouth University Press. 
Zajac, E., and J. Westphal

2004 'Should sociological theories venture into 'economic territory?' Yes!' American Sociological Review 69: 466-471. 